\title{
REGIONAL VARIATIONS IN STILLBIRTH AND RELATION BETWEEN EXTRAMARITAL BIRTH AND STILLBIRTH IN BULGARIA
}

\author{
Dima K. Tsanova, \\ Toni Y. Vekovi
}

Department of Public Health

Sciences,

Medical University - Pleven, Bulgaria

${ }^{1}$ Department of Pharmaceutical

Sciences and Social Pharmacy,

Medical University - Pleven, Bulgaria

\section{Corresponding Author:}

Dima K. Tsanova

Department of Public Health Sciences, Medical University - Pleven

1, Sv. KlimentOhridski Str.

Pleven 5800,

Bulgaria

e-mail:d_krumova@abv.bg

Received: January 18, 2018

Revision received: February 21, 2018

Accepted: June 26, 2018

\section{Summary}

Stillbirth rate is an essential indicator of population health and is much more common than presumed. In 2014, it was 7.34\% in Bulgaria. These trends are seen against the background of a continuous process of increasing proportion of births to unmarried women. This report aims to investigateand conduct a comparative analysis of indicators of stillbirth and extramarital births in Bulgaria for a 15-year period. The data was derived from the National Statistical Institute (NSI) and Eurostat and statistically processed with Statistical Package for Social Science version 24.0 (SPSS v.24.0). The correlation coefficient of Pearson was used to establish the relationship between stillbirth rates and extramarital births.

Despite the technological progress of contemporary medicine, the stillbirth rate in Bulgaria during the last 15 years remained almost the same - from $7.48 \%$ in 2000 to $7.34 \%$ in 2014 . One of the factors that may increase the risk for stillbirth is the marital status of the mother. The proportion of extramarital stillbirths for the country was $74.70 \%$ of all stillbirths for 2014 , but in several districts, this proportion was $100 \%$. Extramarital births and stillbirth rate in Bulgaria seem to be related. There are persisting regional differences in Bulgaria. A potential explanation includes health inequalities and welfare differences.

Key words: Bulgaria, extramarital births, stillbirths

\section{Introduction}

Stillbirth rate is a global health problem. It is an essential indicator of population health and is much more common than expected [1]. According to the World Health Organization (WHO) definition, stillbirth is "the death of the fetus after 28 completed weeks of pregnancy". There are many variations between and within countries on how this event is recorded, especially for early stillbirths that occur at 22- to 27-weeks of pregnancy (w.g.). For international comparisons, WHO recommends including the deaths of fetuses whose weigh is at least 1000 g, or of 28 w.g. or more, when weight values are unavailable. However, precise data on birth 
weight or gestational age are difficult to obtain in developing countries [2].

According to Bulgarian legislation, stillbirth is defined as a birth of a dead fetus weighing more than $800 \mathrm{~g}$ and/or the gestational age is more than 25 w.g.

WHO provides data that in 2015 there were 2.6 million stillbirths globally, which means more than 7178 deaths each day. A substantial part of these deaths is registered in developing countries [2]. WHO developed a specific plan "Every newborn: an action plan to end preventable deaths" whose primary goal is to decrease the stillbirth rate to 12 or fewer per 1000 births by 2030 in every country [3]. Reducing the stillbirth rate is an essential part of the United Nations (UN) Sustainable Development Goals adopted by the UN General Assembly in 2015 and the Global health strategy for women, children and adolescents [4].

New evidence from 2016, as reported in the "Ending preventable stillbirths" series in the Lancet, shows that the stillbirth rate continues to be a problem worldwide. When comparing data for a 15-year period (2000 to 2015), some progress was observed, but the reduction was slower as compared to the achievements made to decrease maternal, neonatal, post-neonatal and under-5 deaths as targeted in the Millennium Development Goals. The vast majority of stillbirths occur in low-income countries, in the places with more socioeconomically disadvantaged residents $[5,6]$.

The burden of stillbirth continues to affect a large number of parents in the 21 st century. For the European region, the indicator is around $7 \%$. The rate in Bulgaria is comparable 7.34\% (2014) [7]. The larger part of stillbirths is preventable, visible by the regional variation between countries. Furthermore, there is a strong correlation with the access to maternal healthcare.

There are huge differences between regions in the country. These trends are seen against the background of a continuous increase of the proportion of births to unmarried women. This indicator may be included in the group of other potential social and behavioral interventions that are identified as risk factors for stillbirths.

The proportion of births to unmarried women has continued to increase, showing new patterns of family formation alongside the more traditional one, where children were born within marriage. Extramarital births occur in nonmarital relationships, among cohabiting couples and to single parents. The proportion of outof-wedlock children increased in the European Union (EU) from $27.3 \%$ in 2000 to $42.0 \%$ in 2014. In 2015, extramarital births outnumbered births inside marriages in several EU member states: France (59.1\%), Bulgaria (58.6\%), Estonia and Slovenia (57.9\%), Sweden (54.7\%), Denmark (53.8\%) and Portugal $(50.7 \%)[8,9]$.

In fact, most extramarital births today are to cohabiting couples. Therefore, while most of these children have their biological parents present at birth, many spend most of their lives in a single-parent family. From the very beginning, children born outside of marriage live a life stacked against them. Extramarital birth is related to poor health at birth [10].

This report aims to investigate and conduct a comparative analysis of indicators of stillbirths and extramarital births in Bulgaria for a 15-year period.

\section{Materials and Methods}

A descriptive epidemiologic study design was used to analyze the stillbirth rate in Bulgaria, based on the data available from the National Statistical Institute (NSI) and Eurostat. Descriptive statistics for qualitative variables were also used. Based on the published absolute numbers of liveborns, stillborns and extramarital stillborns appropriate rates and proportions for the country as a whole, and different districts were calculated for the period 2000-2014. The data were statistically processed with Statistical Package for Social Science version 21.0 (SPSS v.21.0). To establish the relationship between stillbirth rates and extramarital births the correlation, the coefficient of Pearson was used.

\section{Results}

Despite the technological progress of contemporary medicine, the rate of stillbirths in Bulgaria has remained almost unchanged 7.48\%o for 2000 and $7.34 \%$ for 2014 . 


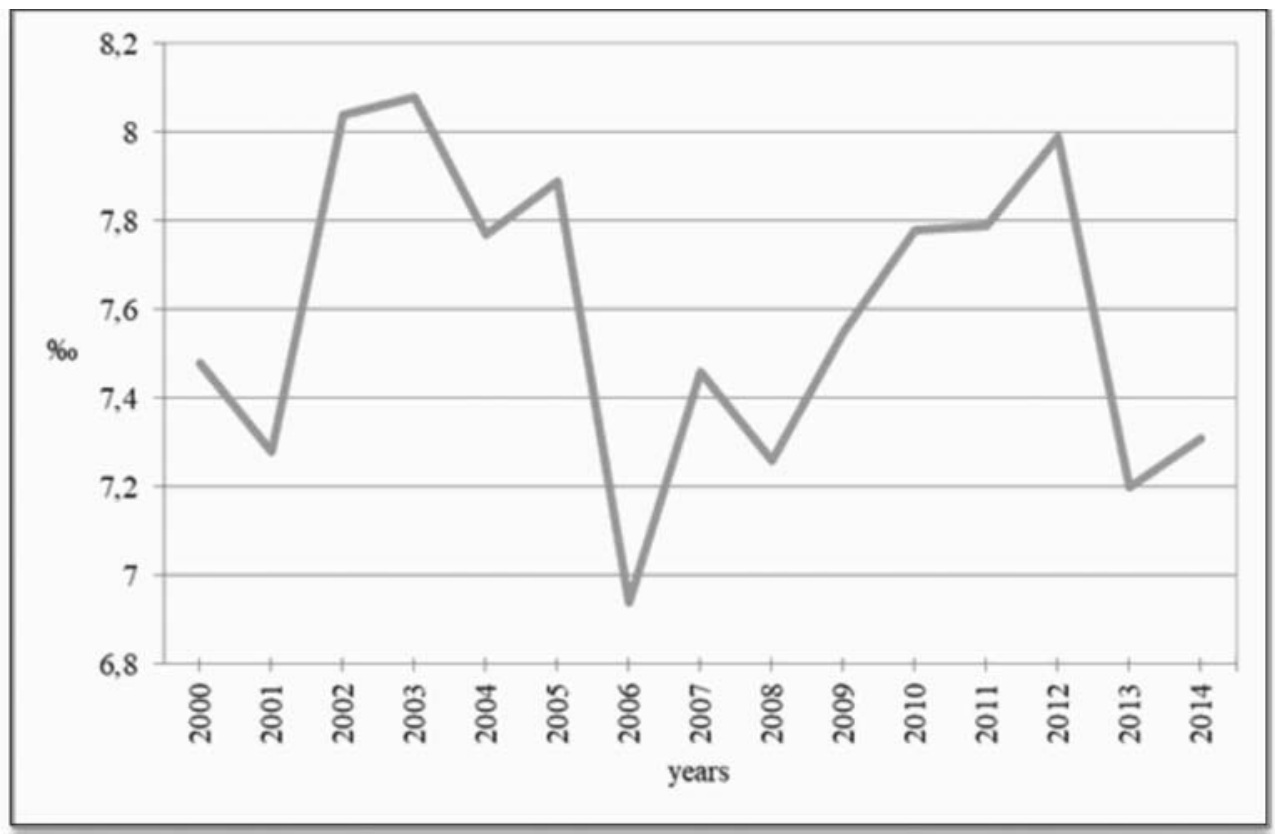

Figure 1. Stillbirth rates in Bulgaria, 2000-2014, \%o

The prevalence of stillbirths varied significantly among regions of the country. Regional variations ranged from $14.97 \%$ in Vidin, $15.67 \%$ in Lovech, $12.49 \%$ in Kardzhali district to $2.57 \%$ in Gabrovo, 2.70\% in Smolyan and 3.90\% in
Sofia (city), as can be seen in Figure 2. The last three regions achieved stillbirth rates equal to the best performing countries. Differences by regions are an important issue in a small country such as Bulgaria.

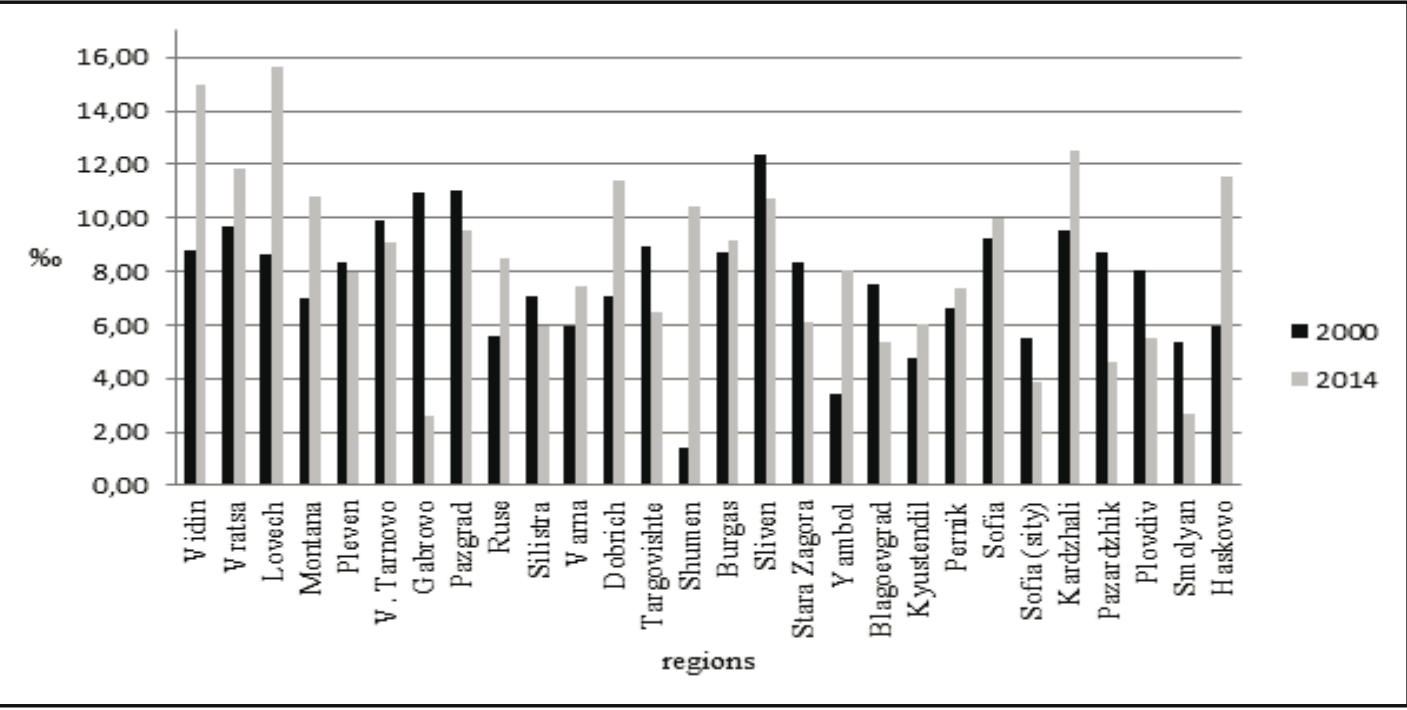

Figure 2. Regional stillbirth rates in Bulgaria, 2000-2014, \%o

One of the maternal demographic characteristics that may increase the risk for stillbirth is the marital status of the mother. The birth of a child out-of-wedlock is an important issue of public health. For the EU, the proportion of extramarital births has increased from $29.5 \%$ in 2002 to $40 \%$ in 2012.

Registered data from NSI show a very high rate of extramarital births in Bulgaria: 38.4\% in 2000 with an increase to $58.9 \%$ in 2014 , as shown in Figure 3. 
Tsanova D, Vekov T. Regional variations in stillbirth and relation between...

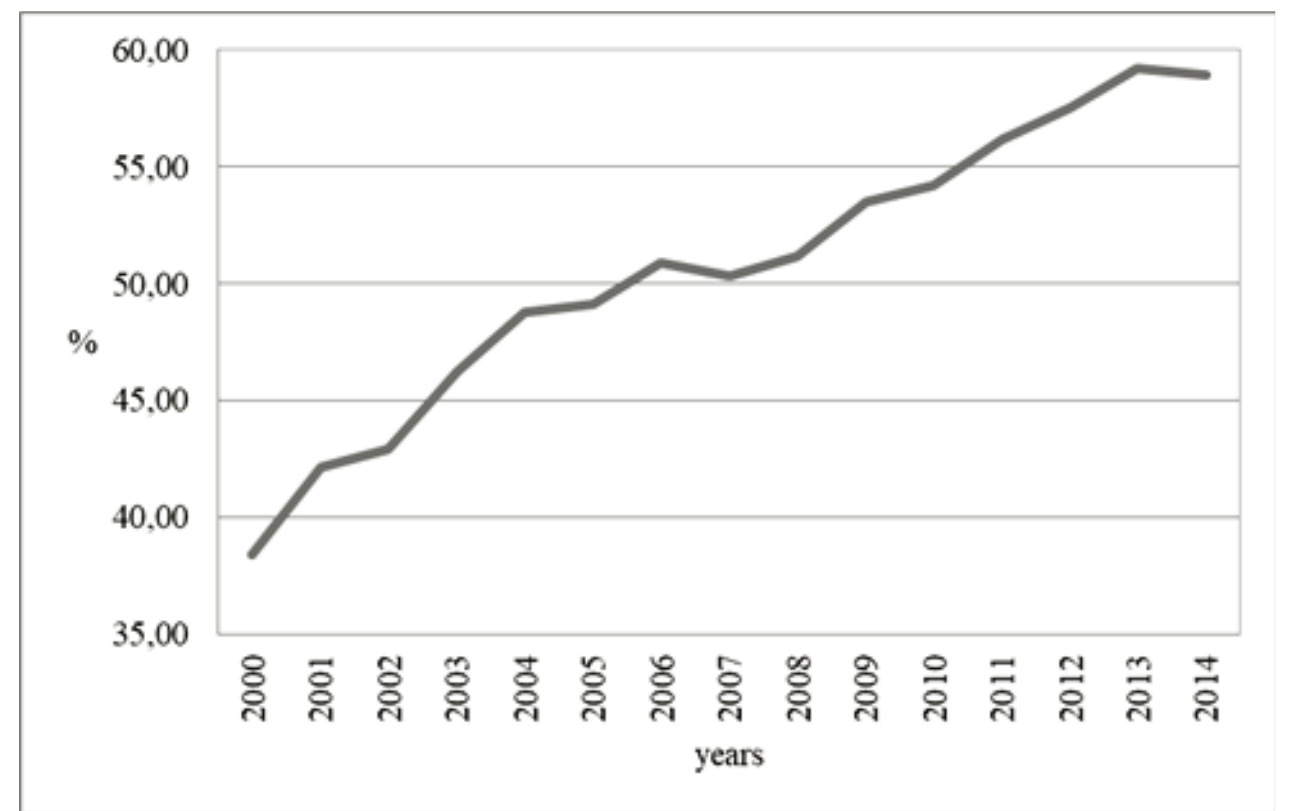

Figure 3. Extramarital births in Bulgaria, 2000-2014, \%

The results show very rapid adoption of the model of cohabitation in our country. Bulgaria very quickly, just for 20-30 years, has overtaken highly developed countries like the Scandinavian counties regarding the proportion of children born out-of-wedlock. The majority of the population chooses new standards and model of coexistence. In all regions, the proportion of extramarital births is increasing. An important characteristic that has been observed in the recent years is a slowdown in growth. Most likely, the threshold of non-marital births is reached, and this level will be kept [10].

The next indicator that we calculated was the proportion of extramarital stillbirths. As shown on Figure 3, this indicator shows a very high level in Bulgaria with a tendency to increase - from $44.68 \%$ in 2000 to $74.70 \%$ in 2014 . Moreover, there are four districts where all stillbirths are outside of marriage - Vidin, Gabrovo, Pernik and Smolyan.

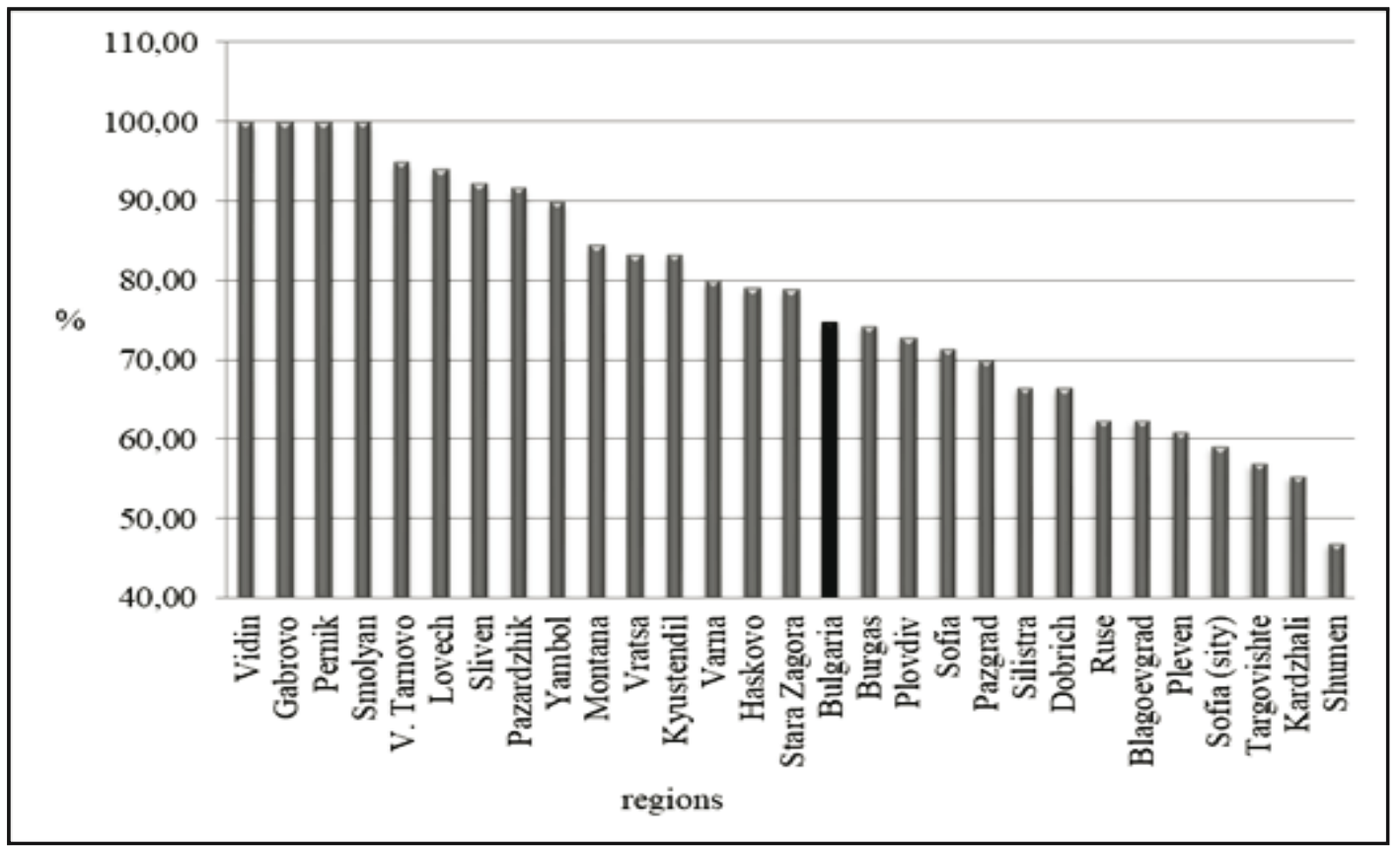

Figure 4. Regional proportion of extramarital stillbirths in Bulgaria, 2014, \% 
The results from the statistical data analysis show that there is a positive linear correlation between stillbirths and extramarital births (Figure 5). The correlation coefficient of Pearson is 0.996, Sig. (2-tailed $)=0.001$. The relationship is significant with $\mathrm{p}=0.001$, which is less than 0.01 . The relationship between these two variables is very high, with $r^{2}=0.783$, which means that $78 \%$ of the trends could be explained by the marital status of the mothers.

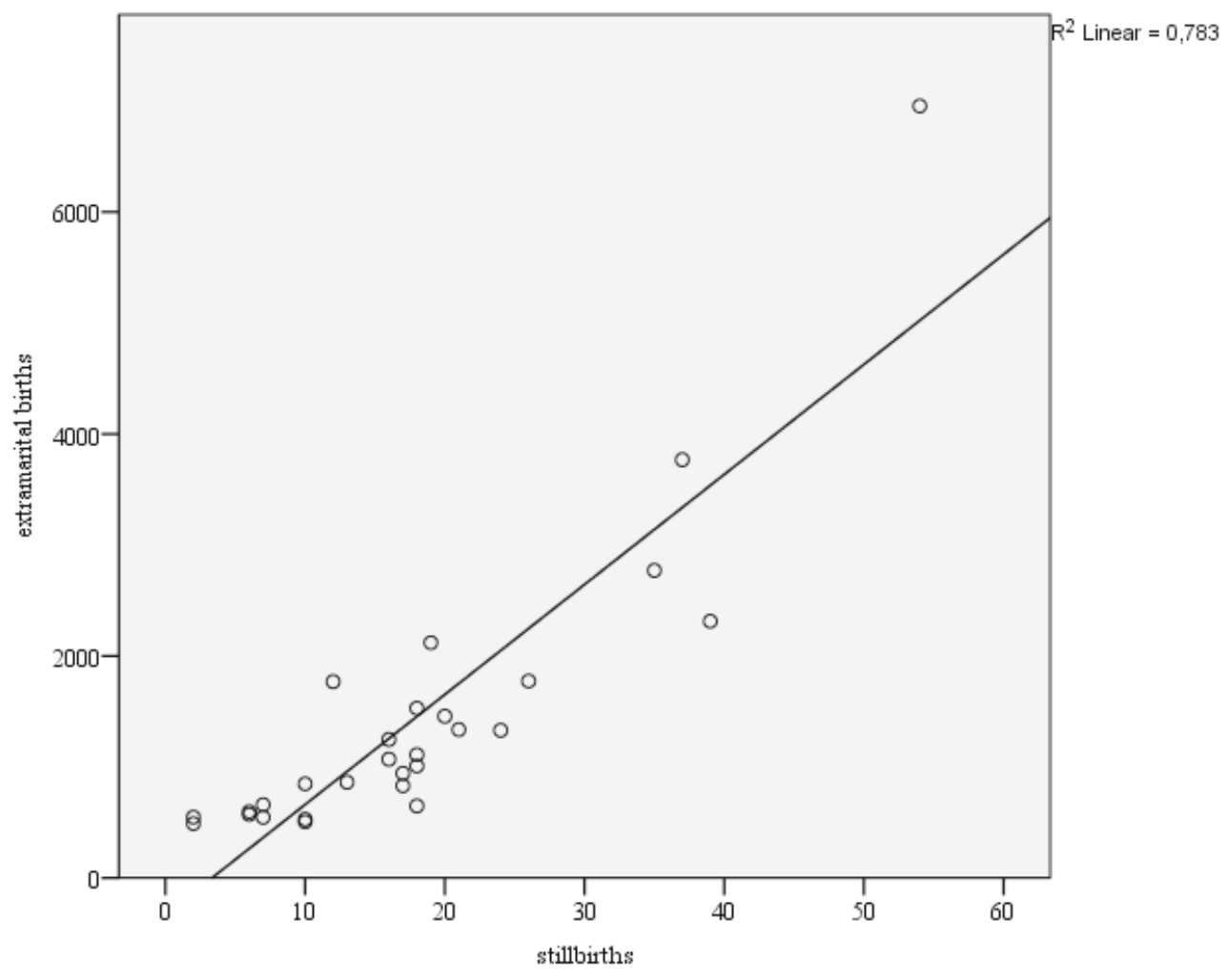

Figure 5. Scattergram and linear correlation between stillbirths and extramarital births in Bulgaria, 2014

\section{Discussion}

Stillbirth is among the most severe complications of pregnancy and still happens much too often. The number of stillbirths has been decreasing globally, but there is yet something to be done even in developed countries. Risk factors for stillbirths have been identified in an attempt to define the women at higher risk but they are nonspecific, and it is difficult to find the relation in all cases [11].

The causes of many stillbirths remain unknown. Stillbirths are related to a wide range of maternal demographic characteristics [12, 13].

To our knowledge, there are no publications in the literature regarding the marital status of mothers as a risk factor for stillbirth. It is well known that this event is very strongly affected by various socio-demographic characteristics.
The study analyses the role of marriage in stillbirth rates in Bulgaria. Extramarital births and stillbirth rate in Bulgaria seem to be related. There are persisting regional differences in stillbirth rates in Bulgaria. One possible explanation includes health inequalities and welfare differences. Our study defined that marital status is one of the risk factors to be considered, even in developed countries, where the effects of marital status are less strong nowadays. We identified a relatively close association between stillbirth rate and extramarital births with a high and very high level of the correlation coefficient.

\section{Conclusions}

The social determinants of health, originating from the democratic changes and impacting the current health, social, and economic inequities, play an important role in our country. 
The costs of stillbirth need to be taken into account when considering whether interventions to prevent stillbirth are cost-effective. Improved antenatal care for unmarried women - family planning, education, and poverty alleviation, can help reduce risk factors for stillbirth.

Still, specific actions for stillbirths are necessary to be taken - new policy formulation, monitoring, as well as research, strong leadership worldwide and in Bulgaria. Institutions with a mandate to lead global efforts for mothers and their babies must assert their leadership to reduce stillbirths by promoting healthy and safe pregnancies.

\section{Acknowledgements}

This study has no financial support.

\section{References}

1. Reinebrant HE, Leisher SH, Coory M, Henry S, Wojcieszek AM, Gardener G, et al. Making stillbirths visible: a systematic review of globally reported causes of stillbirth. BJOG. 2018;125(2):212-24.

2. WHO. Maternal, newborn, child and adolescent health [Internet] 2014. Geneva [cited 2018 Jan 29]: [about 1 screen] Available from: http://www.who. int/maternal_child_adolescent/epidemiology/ stillbirth/en/

3. WHO. Every newborn: an action plan to end preventable deaths [Internet] 2014. Geneva [cited 2018 Jan 29] Available from: http://apps.who.int/iris/bitstream/ handle/10665/127938/9789241507448_eng.pdf; sessionid=668161FB5293B1F6E7BAB5EA9CD $04 \mathrm{C} 27$ ? sequence $=1$
4. United Nations. 17 Sustainable Development Goals (SDGs). [Internet] 2015. Geneva [cited 2018 Jan 29] Available from: http://www.un.org/ sustainabledevelopment/

5. Lawn JE, Blencowe H, Waiswa P, Amouzou A, Mathers C, Hogan D, et al. Stillbirths: rates, risk factors, and acceleration towards 2030. Lancet. 2016;387(10018):587-603.

6. United Nations. Millennium Development Goals (MDGs) [Internet] 2015. Geneva [cited 2018 Jan 29] Available from: http://www.un.org/ millenniumgoals/

7. NSI. Infostat [Internet]. Sofia [cited 2018 Jan 29] Available from: https://infostat.nsi.bg/infostat/ pages/external/login.jsf

8. Eurostat. Statistics Explained: Marriage and divorce statistics [Internet]. Luxembourg [cited 2018 Jan 29], Available from: http://ec.europa. eu/eurostat/statistics-explained/index.php/ Marriage_and_divorce_statistics\#A_rise_in births_outside_marriage

9. Marripedia. Effects of out-of-wedlock birth on children [Internet]. Rockford [cited 2018 Jan 29] Available from: http://marripedia.org/effects_of_ out-of-wedlock_births_on_children

10. Kaloyanov T. Extramarital birth-rate in the Republic of Bulgaria - trends and territorial differences during the 1995-2015 period. Scientific papers of University of National and World Economy. 2017;1(1):11-33.

11. Page JM, Silver RM. Interventions to prevent stillbirth. Seminn Fetal Neonatal Med. 2017;22(3):135-45.

12. Gordon CS. Screening and prevention of stillbirth, Best Prac tRes Clin Obstet Gynaecol. 2017 Jan:71-82.

13. Kamburova, M, Hristova P, Georgieva S, Khan A. Adverse effects of maternal age, weight and smoking during pregnancy in Pleven, Bulgaria. SEEJPH. 2015;(4):39-48. 